ORIGINAL ARTICLE

\title{
Cigarette smoking, occupational exposure to noise, and self reported hearing difficulties
}

\author{
K T Palmer, M J Griffin, H E Syddall, D Coggon
}

Occup Environ Med 2004;61:340-344. doi: 10.1136/oem.2003.009183

\begin{abstract}
Aims: To explore the interaction of smoking and occupational exposure to noise as risk factors for hearing difficulty in the general population.

Methods: A questionnaire was mailed to 21201 adults of working age, selected at random from the agesex registers of 34 British general practices, and to 993 members of the armed services, randomly selected from pay records. Questions were asked about smoking habits, years spent in a noisy occupation, difficulty in hearing conversation, and wearing of a hearing aid. Associations of hearing difficulty with smoking habit were examined by logistic regression and compared across strata of noise exposure, with adjustment for potential confounders.

Results: Around half of the respondents had ever smoked, and half of these still smoked. Among 10418 who provided details on hearing, 348 were classed as having moderate and 311 as having severe hearing difficulty. Risk of hearing difficulty was $3-5$-fold higher in those employed for $>5$ years in noisy work compared with those never employed in a noisy job. Within strata of noise exposure (including those who had never worked in a noisy job), ex-and current smokers had a higher risk of hearing difficulty than lifetime non-smokers. The additional risks were small compared with those of long term noise exposure, and the combination of effects was more consistent with an additive than a multiplicative interaction.

Conclusions: Smoking may adversely affect hearing, and workers should be encouraged to refrain from both smoking and exposure to noise. However, the extra risk to hearing incurred by smoking in high ambient noise levels is small relative to that from the noise itself, which should be the main target for preventive measures.
\end{abstract}

See end of article for authors' affiliations

S ensorineural deafness is a common and important source of disability at older ages, often caused by noise at work. A recent survey suggested that some 153000 men and 26000 women in Britain aged 35-64 years are severely deaf because of workplace noise. ${ }^{1}$ The hazard is well recognised and subject to various controls and checks, such as elimination of sources of noise, enclosure of noisy machinery, reduction of exposure times, use of ear defenders, and audiometry. Control of the hazard might be further improved if factors could be identified that modify susceptibility to noise and which place noise exposed workers at particular risk of deafness.

Cigarette smoking has attracted growing interest in this respect. Evidence on its relation to hearing loss has accrued from health screening programmes, ${ }^{23}$ occupational programmes of hearing conservation, ${ }^{4-9}$ and a few population based surveys. ${ }^{10-14}$ In general these have suggested that smokers have a greater risk of hearing loss than nonsmokers, ${ }^{2-4} 8-1013$ but there have been some contrary observations. ${ }^{5}{ }^{611} 1214$ Also, uncertainty has been expressed about the role of noise in some of these studies as a possible confounder or potentiator of the relation, and about other limitations such as small sample size and unrepresentativeness of study populations. ${ }^{15}$ In a few studies evidence has been found of a dose-response effect, ${ }^{3}{ }^{13}$ but findings on this have not been entirely consistent.

A need remains, therefore, to confirm the association between cigarette smoking and hearing loss and to assess its relation to noise exposure. If smoking is harmful to hearing, it is important to establish whether its effect in combination with occupational noise exposure is additive or multiplicative. This issue is of importance in the counselling and job placement of noise exposed workers who smoke, but only limited evidence exists about the combined effects of the two hazards. ${ }^{916}$

In 1997-98 we conducted a large postal survey to obtain national estimates of exposure to vibration. Enquiries were also made about hearing difficulties, tinnitus, time spent working in noisy jobs, and smoking habits, and this provided an opportunity to examine the inter-relation of these factors more closely.

\section{METHODS}

Altogether, questionnaires were mailed to 21201 men and women aged 16-64 years chosen at random from the age-sex registers of 163 GPs in 34 general practices across Britain and to 993 randomly selected members of the armed forces. The practices were chosen to give a broad geographical coverage and to ensure that industries with known exposure to vibration (a primary focus of inquiry) were represented in the sample, while members of the armed forces (who are cared for by military rather than civilian doctors) were sampled additionally. A single reminder was sent to non-responders about five weeks later. Details of the sampling methods, questionnaire, and validity of the measuring instruments have been published previously. ${ }^{17} 18$

Among other things, enquiries were made about self reported hearing difficulties, tinnitus, and the wearing of a hearing aid; the total time spent working in noisy places where there was a need to shout to be heard (which roughly equates to noise exposures exceeding $\left.85-90 \mathrm{~dB}(\mathrm{~A})^{19}\right)$; and smoking habits.

Difficulty in hearing was assessed by the question: "How well can you hear a person who is talking to you when he is sitting on your right [left] side in a quiet room?". This was modelled on an item from the MRC National Survey of 
Main messages

- The data from this large community based survey support a growing body of evidence that smokers have more hearing difficulty than non-smokers, even after allowance for occupational exposure to noise.

- However, results indicate that noise has a greater effect on hearing than smoking does.

- The risk to hearing in noise exposed workers is not much greater in smokers than in non-smokers.

Hearing, in which the response category "moderate difficulty" corresponded to a measured mean hearing impairment of about $45 \mathrm{~dB}^{20}$ We classed subjects as severely affected if they wore a hearing aid or reported severe hearing difficulty in the worse affected ear; as being moderately affected if they reported moderate hearing difficulty in the worse ear; and as normal if they reported only slight hearing difficulty in the worse ear or no difficulty at all. (In those who only reported on hearing in one ear, the category was that for the ear on which information was given.) Tinnitus was identified by asking: "During the past 12 months have you had noises in your head or ears (such as ringing, buzzing or whistling) which lasted longer than five minutes?" It was defined as "persistent" if it was reported to occur most or all of the time. A smoker was defined as someone who had smoked at least once a day for a month or longer, and classed according to whether he or she still smoked regularly (current smoker) or did not (former smoker).

Information was also collected on age and sex as potential confounding factors, and on complaints of frequently feeling tired or stressed or suffering frequent headaches, as possible markers of lowered threshold for reporting symptoms in general. All statistical analyses were carried out in STATA, release $5 .^{21}$ Associations of hearing impairment and tinnitus with smoking were examined by logistic regression, with adjustment for potential confounding. Separate analyses were conducted according to duration of employment in a noisy occupation. The findings were expressed as prevalence ratios (PRs) with associated 95\% confidence intervals (CIs). These were derived from the corresponding odds ratios using a formula proposed by Zocchetti and colleagues. ${ }^{22}$

\section{RESULTS}

Questionnaires were returned by 12907 subjects (58\% of those selected for study), with a higher response rate in older subjects and women. The occupational distribution of responders was generally similar to that in the preceding national census. ${ }^{23}$ Further details on the response pattern have been published elsewhere. ${ }^{17}$

The respondents included 3184 current smokers, 3329 former smokers, and 6394 lifelong non-smokers. Nonsmokers tended to be younger and reported working fewer years in a noisy occupation than ex- and current smokers.

Among 10418 respondents who provided details on hearing, 9759 were classed as having slight or no hearing difficulty, 348 as having moderate hearing difficulty, and 311 as having severe hearing difficulty (including 165 who wore a hearing aid). Persistent tinnitus was reported by 527 subjects. As reported previously, ${ }^{1}$ the prevalence of tinnitus was higher in those with hearing difficulties (about twice as common in age standardised comparisons), and both symptoms were more common at older ages. Subjects who felt frequently tired or stressed, or suffered frequent headaches, also reported such problems more often.
Policy implications

- Workers should be encouraged not to smoke and to avoid excessive exposure to noise.

- However, there is no strong need to limit the employment of smokers to a greater extent than non-smokers in jobs where ambient noise levels are significant.

Table 1 shows the association of hearing difficulties and tinnitus with smoking habit and years in noisy work, after adjustment for report of tiredness, stress, and headaches, and for age and sex. The baseline for comparison was subjects who were free of auditory problems, and all risks were estimated relative to those of non-smokers who had never worked in a noisy job.

The risks of moderate-to-severe hearing difficulty, severe hearing difficulty, and persistent tinnitus increased with years spent in noisy work for all categories of smoking habit, being some three to five fold higher in those employed for more than five years than in those never employed in noisy work.

Within strata of noise exposure, ex- and current smokers had a moderately higher risk of hearing difficulty than lifetime non-smokers in most comparisons. For example, the PR for moderate-to-severe hearing difficulty was 1.5 (95\% CI 1.1 to 2.1 ) in current versus never-smokers without exposure to noise at work. By contrast, after allowance for age and duration of noisy employment, smoking status was only weakly related to tinnitus if at all.

The combined effect on hearing difficulty of current smoking and long term noise exposure was generally less than multiplicative, and more consistent with an additive effect. Thus, among subjects with moderate-to-severe hearing difficulty, the risk difference between smokers and nonsmokers was similar in every stratum of years employed in noise; and the same was true among subjects with severe hearing difficulty who had never worked in a noisy job or had been employed in it for up to five years. In those with severe hearing difficulty who had been employed for more than five years in a noisy job, the risk difference between smokers and non-smokers was greater, but the interaction was still less than multiplicative.

\section{DISCUSSION}

This population based survey tends to confirm that smoking is associated with hearing difficulty, and that this relation exists even in those who have never been exposed to occupational sources of noise. However, it indicates that any such effect is modest in comparison with long term employment in a noisy job, and that the combined effects of smoking and noise are additive rather than multiplicative.

A strength of our survey was the large, geographically dispersed, and well defined sampling base, which included over 22000 randomly selected subjects across England, Wales, and Scotland. The distribution of occupations in respondents was nationally representative, being similar to that at the preceding national census.

Participation was incomplete (response rate 58\%), but response bias would only explain the association of smoking with hearing difficulty if smokers with symptoms participated more readily than smokers without. This seems unlikely, and similar associations were found in those who responded to the questionnaire at the first invitation and those who required a reminder (data not presented), providing evidence against this pattern of bias. 


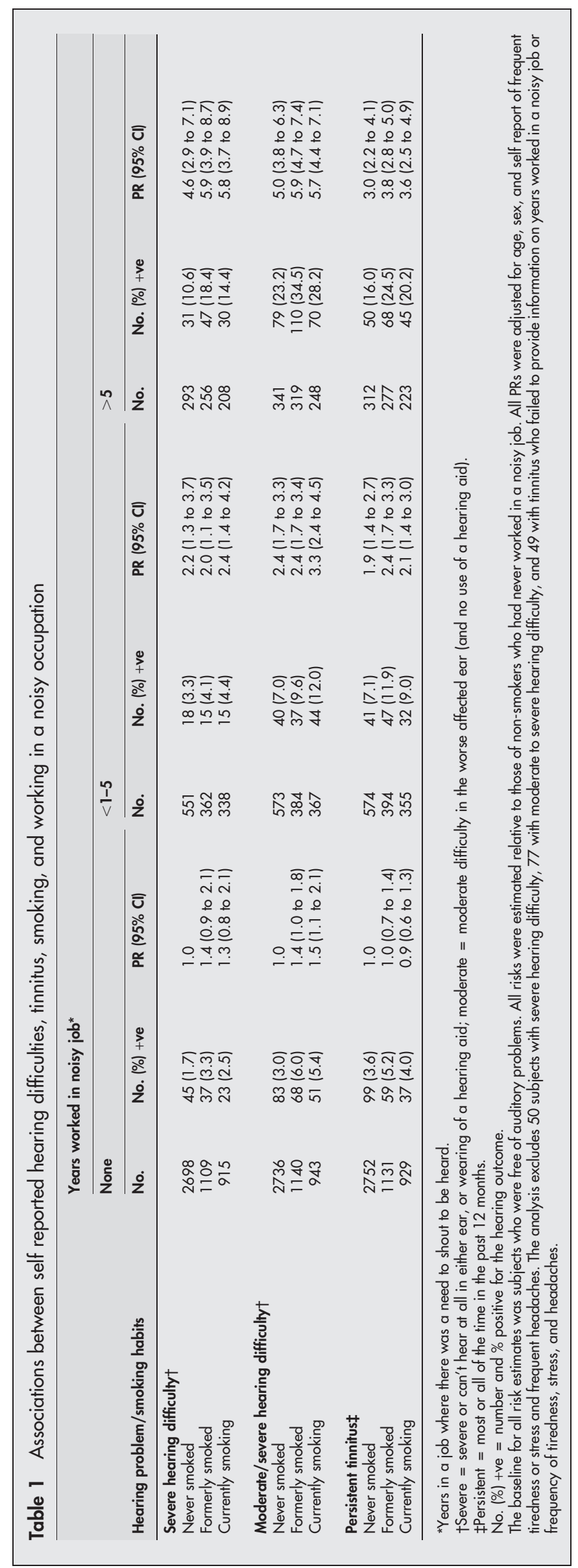


In view of the relatively small number of working aged subjects reporting hearing loss, smoking status rather than pack-years of smoking was used as the index of exposure. This precluded examination of a dose-response relation, but subjects are less likely to have been misclassified using this metric of exposure. Major error arising from the question on hearing impairment also seems unlikely, as the validity of this item has previously been established. ${ }^{20}$ However, our metric of exposure to noise (years worked in a noisy job where there was a need to shout to be heard) was crude to the extent that it did not fully reflect intensity of noise above a likely threshold of $85-90 \mathrm{~dB}(\mathrm{~A})$. Among noise exposed workers, differences in intensity of noise exposure or degree of compliance with wearing of ear defenders may have existed by smoking status. This may have caused residual confounding after allowance for years of employment in noise, but cannot explain the increased risk in smokers who had never held a noisy job.

A number of other potential explanations for the association need to be considered. Smokers may have reported hearing difficulty more readily than non-smokers, perhaps as part of a general tendency to report somatic symptoms at a lower threshold; but the association persisted despite adjustment for markers of such a tendency (frequent complaints of headaches, tiredness, and stress).

Alternatively, assuming a genuine effect, smoking may act as a direct ototoxin, ${ }^{24}$ may impair blood flow to the cochlea by inducing vasospasm, atherogenic narrowing, and thrombotic occlusion of the nutrient arteries; ${ }^{525}$ or may alter blood viscosity, ${ }^{15} 26$ or generate carboxyhaemoglobin, ${ }^{27} 28$ exacerbating any problems of local hypoxia.

There have been only a few population based surveys of smoking and hearing loss previously. When 1662 elderly subjects from the Framingham study underwent audiometric screening, no association was found between hearing thresholds and current smoking status or number of cigarettes smoked. ${ }^{11}$ And hearing thresholds in middle age did not deteriorate more rapidly during follow up among smokers than non-smokers from rural Denmark. ${ }^{14}$ But in the US Health Interview Survey, ${ }^{10}$ men who smoked two or more packs per day more often reported hearing problems than non-smokers; in a population based cross-sectional survey based in Beaver Dam, USA, ${ }^{13}$ a $25 \mathrm{~dB}$ hearing loss in the worse ear was 1.7 times more common in current smokers than lifetime non-smokers after adjustment for other factors; and in another study, which sampled non-smokers from the community, a moderately increased risk of hearing loss (OR 1.3) was found in association with exposure to environmental tobacco smoke. ${ }^{29}$

Surveys set within programmes of health screening and hearing conservation have produced some of the most convincing evidence that smoking is detrimental to hearing. For example, in Japan, where labour law mandates periodic audiometry for all employees irrespective of noise exposure, two large surveys found worse hearing among smokers than non-smokers in non-noisy white collar occupations, and a dose-response effect among current smokers which was much clearer for high frequency hearing loss than for low frequency loss. ${ }^{3}$ Mizoue and colleagues ${ }^{9}$ have suggested that inner ear cells responsible for high frequency hearing are more vulnerable to ischaemic damage, as they are located at the end of nutrient arteries, and that the inconsistency of findings across studies may reflect failure to distinguish the different potential patterns of hearing loss.

The combined effects of noise and smoking have only occasionally been explored. In keeping with our findings, Mizoue et al reported an additive effect, based on periodic health data from 4624 Japanese steel company workers. ${ }^{9}$ But by contrast, Prince et al found that the combined effect of these risk factors was more than that from simple additivity. ${ }^{16}$

Workers should be encouraged as a matter of good public health policy to avoid the hazards of both noise and smoking. But our results suggest that from the viewpoint of hearing there is no strong imperative to limit the employment of smokers to a greater extent than non-smokers where ambient noise levels are significant. Counselling may be appropriate in these circumstances, but our data indicate only a small additional risk from smoking and underscore the importance of noise as the primary target for preventive measures in hearing conservation programmes.

\section{ACKNOWLEDGEMENTS}

This study was supported by a grant from the Health and Safety Executive. We thank the Royal College of General Practitioners, the Primary Care Rheumatology Society, and the general practices for help in assembling the mailing lists, and the MRC staff who were involved in data handling. Professor Adrian Davies kindly recommended the questions on hearing difficulty and tinnitus. Denise Gould prepared the manuscript.

\section{Authors' affiliations}

K T Palmer, H E Syddall, D Coggon, MRC Environmental Epidemiology Unit, Community Clinical Sciences, University of Southampton, UK M J Griffin, Institute of Sound and Vibration Research, University of Southampton, UK

\section{REFERENCES}

1 Palmer KT, Griffin MJ, Syddall HE, et al. Occupational exposure to noise and the attributable burden of hearing difficulties in Great Britain. Occup Environ Med 2002;59:634-9.

2 Siegelaub AB, Friedman GD, Adour K, et al. Hearing loss in adults. Relation to age, sex, exposure to loud noise, and cigarette smoking. Arch Environ Health 1974;29:107-9.

3 Nakanishi N, Okamoto M, Nakamura K, et al. Cigarette smoking and risk of hearing impairment: a longitudinal study in Japanese male office workers. J Occup Environ Med 2000;42:1045-9.

4 Thomas GB, Williams GE, Hoger NG. Some non-auditory correlates of the hearing threshold levels of an aviation noise exposed population. Aviat Space Environ Med 1981:52:531-6.

5 Barone JA, Peters JM, Garabrant DH, et al. Smoking as a risk factor in noiseinduced hearing loss. J Occup Med 1987;29:741-5.

6 Pyykko I, Koskimies K, Starck J, et al. Risk factors in the genesis of sensorineural hearing loss in Finnish forestry workers. Br J Ind Med 1989;46:439-46.

7 Fuortes LJ, Tang S, Pomrehn P, et al. Prospective evaluation of associations between hearing sensitivity and selected cardiovascular risk factors. Am J Ind Med 1995;28:275-80.

8 Starck J, Toppila E, Pyykko I. Smoking as a risk factor in sensorineural hearing loss among workers exposed to occupational noise. Acta Otolaryngol 1999; 119:302-5.

9 Mizove T, Miyamoto T, Shimizu T. Combined effect of smoking and occupational exposure to noise on hearing loss in steel factory workers. Occup Environ Med 2003;60:56-9.

10 National Center for Health Statistics. Data from the National Health Survey: cigarette smoking and health characteristics, July 1964-June 1965. Vital Health Statistics $101967 ; 34: 11,14$.

11 Gates GA, Cobb JL, D'Agostino RB, et al. The relation of hearing in the elderly to the presence of cardiovascular disease and cardiovascular risk factors. Arch Otolaryngol Head Neck Surg 1993;119:156-61.

12 Brant L, Gordon-Salant S, Peason JD, et al. Risk factors related to ageassociated hearing loss in the speech frequencies. J Am Acad Audiol 1996;7:152-60.

13 Cruickshanks KJ, Klein R, Klein BEK, et al. Cigarette smoking and hearing loss. The Epidemiology of Hearing Loss Study. JAMA 1998;279:1715-19.

14 Karlsmore B, Lauritzen T, Engberg $M$, et al. A five-year longitudinal study of hearing in a Danish rural population aged $31-50$ years. Br J Audiol 2000;34:47-55.

15 Cocchiarella LA, Sharp S, Persky WW. Hearing threshold shifts, white-cell count and smoking status in working men. Occup Med 1995;45:179-85.

16 Prince M, Matanoski G. Problems in ascertaining the combined effects of exposures: results of an occupational cohort study of the joint effects of noise and smoking on hearing acuity. In: Fechter $\mathrm{D}$, ed. Proceedings of the 4th International Conference on the Combined Effects of Environmental Factors. Baltimore: John Hopkins University, 1991:87-91.

17 Palmer KT, Griffin MJ, Bendall H, et al. The prevalence and pattern of occupational exposure to hand-transmitted vibration in Great Britain: findings from a national survey. Occup Environ Med 2000;57:218-28.

18 Palmer K, Coggon D, Griffin MJ, et al. The development of a self-administered questionnaire to assess exposures to hand-transmitted and whole body vibration and their health effects. J Sound Vib 1998;215:653-86. 
19 Health and Safety Executive. Noise at work. Guidance on regulations. London: HMSO, 1989.

20 Davis AC. The prevalence of hearing impairment and reported hearing disability among adults in Great Britain. Intl J Epidemiol 1989;18:911-17.

21 StataCorp. Stata Statistical Software: release 5.0. College Station, TX: Stata Corporation, 1997.

22 Zocchetti C, Consonni D, Bertazzi PA. Estimation of prevalence ratios from cross-sectional data. Int J Epidemiol 1995;24:1064-5.

23 Office of Population Censuses and Surveys. Census 1991: Economic activity report. London: HMSO, 1993.

24 Hultcrantz E, Hillerdahl M, Angelborg C. Effect of nicotinic acid on cochlear blood flow. Arch Otolaryngol 1982;234:151-5.
25 Rubinstein M, Hildesheimer M, Muchnik C. Chronic labyrinthine ischemia. $J$ Laryngol Otol 1988;102:496-9.

26 Browning GG, Gatehouse S, Lowe GD. Blood viscosity as a factor in sensory neural hearing impairment. Lancet 1986;i:121-3.

27 Stewart RO. The effect of carbon monoxide on humans. J Occup Med 1976;18:304-9.

28 Chung DY, Wilson GN, Gannon RP, et al. Individual susceptibility to noise. In: Hamenik RP, Henderson D, Salvi R, eds. New perspectives on noise-induced hearing loss. New York: Raven Press, 1982:511-19.

29 Iribarren C, Friedman GD, Klatsky AL, et al. Exposure to environmental tobacco smoke: association with personal characteristics and self reported health conditions. J Epidemiol Community Health 2001;55:721-8.

\section{Clinical Evidence - Call for contributors}

Clinical Evidence is a regularly updated evidence based journal available worldwide both as a paper version and on the internet. Clinical Evidence needs to recruit a number of new contributors. Contributors are health care professionals or epidemiologists with experience in evidence based medicine and the ability to write in a concise and structured way.

\section{Currently, we are interested in finding contributors with an interest in} the following clinical areas:

Altitude sickness; Autism; Basal cell carcinoma; Breast feeding; Carbon monoxide poisoning; Cervical cancer; Cystic fibrosis; Ectopic pregnancy; Grief/bereavement; Halitosis; Hodgkins disease; Infectious mononucleosis (glandular fever); Kidney stones; Malignant melanoma (metastatic); Mesothelioma; Myeloma; Ovarian cyst; Pancreatitis (acute); Pancreatitis (chronic); Polymyalgia rheumatica; Post-partum haemorrhage; Pulmonary embolism; Recurrent miscarriage; Repetitive strain injury; Scoliosis; Seasonal affective disorder; Squint; Systemic lupus erythematosus; Testicular cancer; Varicocele; Viral meningitis; Vitiligo However, we are always looking for others, so do not let this list discourage you.

\section{Being a contributor involves:}

- Appraising the results of literature searches (performed by our Information Specialists) to identify high quality evidence for inclusion in the journal.

- Writing to a highly structured template (about 2000-3000 words), using evidence from selected studies, within 6-8 weeks of receiving the literature search results.

- Working with Clinical Evidence Editors to ensure that the text meets rigorous epidemiological and style standards.

- Updating the text every eight months to incorporate new evidence.

- Expanding the topic to include new questions once every 12-18 months.

If you would like to become a contributor for Clinical Evidence or require more information about what this involves please send your contact details and a copy of your CV, clearly stating the clinical area you are interested in, to Claire Folkes (cfolkes@bmigroup.com).

\section{Call for peer reviewers}

Clinical Evidence also needs to recruit a number of new peer reviewers specifically with an interest in the clinical areas stated above, and also others related to general practice. Peer reviewers are health care professionals or epidemiologists with experience in evidence based medicine. As a peer reviewer you would be asked for your views on the clinical relevance, validity, and accessibility of specific topics within the journal, and their usefulness to the intended audience (international generalists and health care professionals, possibly with limited statistical knowledge). Topics are usually 2000-3000 words in length and we would ask you to review between $2-5$ topics per year. The peer review process takes place throughout the year, and our turnaround time for each review is ideally 10-14 days.

If you are interested in becoming a peer reviewer for Clinical Evidence, please complete the peer review questionnaire at www.clinicalevidence.com or contact Claire Folkes(cfolkes@bmigroup.com). 